\title{
ON THE DETERMINATION OF THE SOLAR CHEMICAL COMPOSITION FROM A STUDY OF THE ULTRAVIOLET RESONANCE LINES
}

\author{
by S. R. Pottasch \\ (Sterrenkundig Laboratorium KAPTEYN, Groningen, Holland)
}

RÉsumé. - On montre qu'il est possible d'étudier la composition chimique en supposant que les raies de résonance ultraviolettes sont formées par excitation par chocs suivie d'une transition radiative directe d'un quantum capable de sortir de l'atmosphère. On discute ces hypothèses et la précision des résultats. L'efjet d'inhomogénéités non radiales est aussi discuté. Enfin, on soulève le problème de l'abondance en hydrogène pour lequel on emploie des résultats des observations radioélectriques. Les résultats du présent travail sont comparés à ceux de travaux antérieurs.

ABSTRACT. - On the assumption that the ultraviolet resonance lines are formed by collisional excitation followed by direct radiative transition of a quantum which eventually escapes from the atmosphere, it is shown how the chemical composition may be found. These assumptions are discussed, as is the accuracy of the determinations. The effects of non-radial inhomogeneities are also discussed. Finally the question of the determination of the hydrogen abundance is raised, for which purpose the solar radio observations are used.

The results of this analysis are compared with other solar abundance determinations.

Резюме. - Показано, что возможно исследовать химический состав предполагая, что ултрафиолетовыс резонансные линии образованы возбуждением соударениями с последующим за ним Iрямым лучистым переходом кванта способного выйти из атмосферы. Обсуждены эти гипотезы и точность резлуьтатов. Эффект нерадиальных неоднородностей также обсужден. Наконед, поднят вопрос обилия водородом, для которого использованы результаты радиоэлектрических наблюдений. Результаты настоящей работы сравнены с результатами предшествующих работ.

The question of the effect of dielectronic recombination on the abundance determination has been raised. These recombinations will introduce two changes in the calculations. Firstly the temperature of formation of a given stage of ionization will be raised, and secondly the maximum fraction of a given stage of ionization (present at the most favorable temperature) may be expected to vary somewhat. The first effect is not important in the abundance analysis since the temperature enters the calculations only very weakly. The second effect is difficult to discuss at present, but we may minimize it by obtaining relative abundances from a single isoelectronic sequence. This would indicate that the abundance determinations are probably not in serious error. The new results of BuRGESs, reported at this conference, will enable us to verify this conclusion in the near future.

The important thing to stress, as I see it, is that the determination of the abundances is an inherent part of the analysis of the ultraviolet spectrum and cannot be divorced from it. It is not simply that we are throwing away information if we use abundances from some other source (either the photospheric or the forbidden coronal line analysis), we are destroying, the possibility of obtaining a consistent theory. The internal consistency of the theory is extremely important because it is one of the indications where one must go to better some of the assumptions which have been used in the theory.

Until now the simplest assumptions have gone into the theory. One assumes that :

1) the radiation is formed by collisional excitation followed by radiative cascade ;

2) one half of the radiation formed in the atmosphere escapes ;

3) the analysis should be carried out with observations which refer to one particular time. One has in practice been flexible with this requirement because of the nature of the existing observations.

With these assumptions one can obtain an estimate of the abundances and some information about the atmospheric structure, without our 
Relative Abundances of the Chemical Elements

\begin{tabular}{|c|c|c|c|c|c|}
\hline Element & $\begin{array}{c}\text { CORONA } \\
\text { FORBIDDEN } \\
\text { LINES }\end{array}$ & $\begin{array}{c}\text { CORONA } \\
\text { ULTRAVIOLET } \\
\text { ANALYSIS }\end{array}$ & $\begin{array}{c}\text { Solar } \\
\text { Cosmic } \\
\text { RAYS }\end{array}$ & РHOTOSPHERE & $\begin{array}{c}\text { Stony } \\
\text { Meteorites }\end{array}$ \\
\hline - & - & - & - & - & - \\
\hline $\mathrm{H}$ & $1,000,000$ & $1,000,000$ & & $1,000,000$ & \\
\hline $\mathrm{He}$ & & 200,000 & 107,000 & & \\
\hline $\mathrm{C}$ & & 600 & 590 & 520 & \\
\hline $\mathrm{N}$ & & 60 & 190 & 95 & \\
\hline 0 & & 450 & 1,000 & 910 & \\
\hline $\mathrm{Ne}$ & & 50 & 130 & & \\
\hline $\mathrm{Mg}$ & & 90 & 43 & 25 & 63 \\
\hline $\mathrm{Al}$ & & 5 & & 1.6 & 5 \\
\hline $\mathrm{Si}$ & & 100 & 33 & 32 & 63 \\
\hline $\mathbf{P}$ & & 0.8 & & 0.22 & 0.5 \\
\hline $\begin{array}{l}\mathrm{S} \\
\mathrm{Ar}\end{array}$ & $\begin{array}{l}10 . \\
20\end{array}$ & 14 & 57 & 20 & 7. \\
\hline $\mathrm{K}$ & 0.7 & & & 0.05 & 0.31 \\
\hline $\mathrm{Ca}$ & 6. & 3 & & 1.4 & 4.4 \\
\hline $\mathrm{Cr}$ & 1. & & & 0.23 & 0.8 \\
\hline $\mathrm{Mn}$ & 0.6 & & & 0.078 & 0.4 \\
\hline $\mathrm{Fe}$ & 68 & 40 & 20 & 3.7 & 53. \\
\hline Co & 0.3 & & & 0.043 & 0.2 \\
\hline $\mathrm{Ni}$ & 5. & & $i$ & 0.8 & 3 \\
\hline
\end{tabular}

having to make any assumptions as to the homogeneity of the atmosphere, which is very useful since the latter is a very difficult problem. In fact we may even effectively isolate the problem of the inhomogenities until we bring in the radio frequency observations, at which point we may discuss the matter of inhomogeneities separately.

Let me end by giving the best present results as to abundances, which are shown in the accompanying table. For comparison the results of the coronal forbidden line analysis, the photosphere, the cosmic rays originating in the Sun, and the meteorites are all shown. The meteorite abundances are normalized so that the trace element composition is the same as the photosphere.

Manuscrit reçu le 14 septembre 1964.

Discussion.

C. Pecker-Wimel. - What lines of Fe are used in the abundance determination? Are you sure that they are coming from the same region of the Sun ? (integration over the volume of emission).

S. PotTAsch. - Lines of Fe XIV, XV and XVI have been used in the determination of the iron abundance, with the latter two ions having lines whose identification seems more certain and whose intensity is better known than the former. Comparison of these lines with those of Si XII are made and the ratio iron silicon is obtained from this. One would like additional assurance that the Si XII lines are formed at the same temperature region as the iron liries, and this probably could be obtained observationally if such spectrograms as were described by LINDSAY and NEUPERT also covered the spectral region of the Si XII resonance lines. One may also consider comparing the iron lines with those of 0 VII.
L. BiermanN. - Did you, or did anybody else inquire about the possible influence of the continuous flow of meteoric particles (partly of cometary origin) into the Sun which could, under certain circumstances, affect the coronal abundances of $\mathrm{Fe}$ and some other elements?

S. Pottasch. - Seaton (Plan. Space Sci. 12, 55, 1964) concludes that gravitational diffusive separation will reduce the coronal heavy element concentrations in times of the order of 3 hours, while meteoric infall would only change the coronal composition appreciably in the order of 10 days.

J. Seaton. - Dr. PotTasch had earlier shown that meteor infall is too small, by a factor of at least 100 , to account for the coronal abundance anomalies. This was based on estimates of meteor infall obtained by WHIPPLE. At a recent meeting of the Royal Astronomical Society, Professor UREY suggested that the 
number density of meteors in the vicinity of the Sun might be much greater than in the vicinity of the Earth, in which case, meteor infall might, after all, be important for the corona. I wonder if anyone could comment further on this possibility.

E. Schatzman. - The relative abundances in the corona from $\mathrm{Ca}$ to $\mathrm{Ni}$ seem to be very similar to the relative abundances in the photosphere.

V AN DE HULST. - It does not seem clear that meteor infall should have any influence at all, because the material, after evaporation and ionization, will be carried off again by the solar wind and may not reach the low level about which we are talking now. This, of course, requires a precise computation.

Miss A. B. UNDERHILL. - I recall very recently hearing a report by ALLER and UREY or someone making the point that meteorites are of many different sorts with different chemical composition which have resulted from the different phase-relationships at the time of solidification of the object under study. Thus, a comparison of solar abundances with meteoritic abundances is not surely to be interpreted in a simpleminded way.

S. Potwasch. - I certainly agree. The meteoritic composition given for comparison is that of the chondritic meteorites, which are generally considered (by both ALLER and UREY) to be the best available approach to an average meteor composition in the solar neighbourhood. I think, however, that it is proper to make such a comparison in order to pinpoint the present difficulties.

L. H. Aller. - It is difficult to discuss the abundances of elements in meteorites. Note that stony meteorites are divided in 2 classes : achondrites and chondrites. The achondrites show a diversity of compositions but are more abundant; chondrites show a smaller spread in abundances for the more abundant elements. Nevertheless (cf. UREv, Geophysics Reviews, 1964, p. 1) chondrites show important differences one from another. Enstatite chondrites, ordinary chondrites and carbonaceous chondrites differ in degree of oxidation or reduction. UREY and CRAIG noted that there were two groups of chondrites on basis of their iron abundance. Trace elements show wide divergencies. Another complication comes from the fact that the chondrules differ in composition from the rest of the meteorite. The differences depend on the type of meteorite and vary from one element to another (cf. G. Golms and P. SchmitT). For example, in type II carbonaceous chondrites, the chondrules have about $25 \%$ of the iron content of the meteorite as a whole. 